\title{
The effect of social reinforcement on children's story themes
}

\author{
VICTOR HAYS and ELEANOR WILLEMSEN, ${ }^{1}$ Fresno State \\ College, Fresno, Calif. 93726
}

A task resembling a projective test was administered individually to 21 sixth-grade children. Positive, negative, and neutral social reinforcement was given at various stages in each child's session. It was found that negative social reinforcement reduced the tendency to persist with the original theme. The remaining two reinforcement conditions did not differ.

There is a good deal of evidence in the literature which indicates that a child's responses to experimental tasks are, in part, the result of the E's reactions to those responses. Specifically, such reactions as verbal approval, attention, and the verbal statement "correct" have been shown to function as reinforcers for such response categories as "problem behavior" (Harris, Wolf, \& Baer, 1967), choice behavior (Gewirtz \& Baer, 1958), and discrimination learning (Horowitz, 1967). The effecacy of adult social reinforcement in experimental task situations has been shown to vary with certain situational and subject characteristics. Following social isolation such reinforcement is more effective than following interaction with E (Gewirtz \& Baer, 1958) and is greater for girls and High-Dependent boys than for Low-Dependent boys (Hartup, 1968). An interesting study by Stevenson \& Hill (1965) showed performance of the Ss under conditions of social reinforcement to be poorer following previous failure than following previous success. Social reinforcement did not overcome the general depressing effect of previous failure.

The studies reviewed above all deal with the learning of quite specific responses such as choice between two motor options, utterance of a specific word, and so forth. The present study was undertaken to discover whether or not positive and negative adult verbal responses could differentially affect the content of the stories children tell in a projective test situation.

\section{HYPOTHESES}

It was predicted that Ss would change their themes more often when $\mathrm{E}$ was giving disapproving verbal reactions (negative reinforcement) than they would when he was approving (positive reinforcement). No specific prediction was made about the "no reinforcement" condition, since the meaning of "no response" has been shown to depend on how the $E$ has behaved just prior to the "no response" period (Offenbach \& Meyer, 1964).

\section{SUBJECTS}

Twenty-one children from the sixth-grade class at the Fresno State College Laboratory School served as Ss for the study. There were 11 girls with a mean age of 11.9 years and 10 boys with a mean age of 12.0 years. Twenty additional sixth-grade children from a nearby public elementary school served as judges in selecting the cartoons which constituted the projective stimuli. All Ss were tested by the same young adult male $\mathrm{E}$.

\section{DESIGN}

Each $\mathrm{S}$ served as his own control. E asked him to tell a story about each of three cartoons. For one of the cartoons, $E$ gave verbal approval to S's responses. for one he gave disapproval, and for one he gave no response. The three cartoons and the three reinforcement conditions each appeared equally often in first-, second-, and third-order positions. However, the nine combinations of cartoons and reinforcement conditions were not counterbalanced.

\section{CARTOONS}

Twenty children from the sixth grade at a school in a small community near Fresno were shown 10 cartoons taken from four different "comic books" selected by E. The children indicated their three preferred ones. These data were used to select the three most appealing pictures for use in the experiment. The balloons which show what the characters are saying were marked out; the cartoons were mounted on $8 \frac{1}{2} \times 11$ in. white poster paper. Cartoon 1 showed a little boy immersed in a public fountain with his clothes on the edge; his mother appears to have just arrived and is saying something to him. Cartoon 2 showed an auto accident; a man and a little girl are standing beside a crumpled automobile while the other driver looks on, perplexed. Cartoon 3 showed a detective pointing his revolver at a criminal while Captain Marvel and a young girl look on.

\section{EXPERIMENTAL SESSION}

Subjects were individually called for at their classroom and escorted to the Psychology Building where the observation room was located. Since we wished to avoid any superfluous apprehension in the Ss. E conversed with them pleasantly on the walk between buildings. Specifically. E inquired how $S$ was liking school this year and told him that he would be asked to look at some cartoons when he got to "the room." This part of the session might be regarded as containing mild positive reinforcement which could influence $S$ 's subsequent behavior. Since the condition was approximately constant for all Ss. its effect was not evaluated.

In the experimental room. E seated $S$ by a table near the observation window and sat to S's right. E then placed the first cartoon face down in front of S and gave these instructions: "I want you to make up a story concerning this cartoon. You may want to explain what is happening. or what has led up to this situation, or what is being thought, or what will happen."

The general tone of the instructions urged the $S$ to be as creative as possible and not to think in terms of right and wrong responses.

The $\mathrm{S}$ was allowed to speak for $21 / 2 \mathrm{~min}$ for each story with the appropriate reinforcement given after $30.60,90$, and $120 \mathrm{sec}$. After the instructions, E turned the cartoon face up and handed it to $S$ who then told his story. After $30 \mathrm{sec}, \mathrm{E}$ gave either positive, negative, or no verbal reinforcement. If $S$ was in the middle of a sentence at $30 \mathrm{sec}$. E waited until the sentence was completed. $S$ was then allowed to continue his story for another $30 \mathrm{sec}$, whereupon $E$ again gave a verbal reinforcement. The same general procedure was followed with the second and third cartoons except that the reinforcement conditions were altered. At the conclusion of the session, E thanked $S$ for his cooperation and escorted him back to the classroom.

\section{SCORING}

Three $O s$ watched $E$ and $S$ from behind the one-way vision window. The Os were asked to make judgments concerning when a change of theme occurred. A theme was defined as a subject of discourse, and Os were instructed to tally a new theme whenever the goal-direction of a character's thought. utterance, or action was altered. The average of the three interobserver Pearson Product Moment Correlations was .86. The score for each $S$ was subsequently determined by averaging the three Os' scores. A high number of themes thus indicates more change of response, whereas a low number of themes indicates persistance with the ongoing response. 
Table 1

Means

Reinforcement Conditions

\begin{tabular}{|c|c|c|c|c|c|}
\hline & & Positive & No & Negative & Combined \\
\hline \multirow{3}{*}{ Sex } & Male $(N=10)$ & 1.20 & 1.50 & 1.80 & 1.50 \\
\hline & Female $(N=11)$ & 2.00 & 1.30 & 2.60 & 1.96 \\
\hline & Total Sample & 1.60 & 1.40 & 2.20 & \\
\hline
\end{tabular}

\section{REINFORCEMENT TREATMENTS}

For each of the positive and negative reinforcement conditions, $E$ used three sentences. He repeated the first one after 30 and $60 \mathrm{sec}$; the other two were used, in the order listed, after 90 and $120 \mathrm{sec}$. For the Positive-Reinforcement Condition, these were (a) "I like that," (b) "That's very good," and (c) "That's a good point." For the NegativeReinforcement Condition, the negative counterparts of the preceding statements were used. During the No-Reinforcement Condition, E listened silently to S's story.

\section{RESULTS}

The mean number of theme changes for each condition for both sexes appears in Table 1. The reinforcement conditions were found to differ in the number of themes elicited $[F(2,36)=7.79, p<.05]$. A follow-up comparison of the three pairs of means was performed using the Newman-Keuls procedure (Winer, 1962, pp. $309 \mathrm{ff}$.). It was found that the number of themes produced under the NegativeReinforcement condition was statistically greater than that under either the No-Reinforcement or Positive-Reinforcement conditions. The No-Reinforcement and PositiveReinforcement conditions did not differ from each other.

The main effect of Reinforcement conditions interacted with $\operatorname{Sex}[F(2,36)=8.23, p<.05]$. Follow-up comparisons of cell means revealed that while the difference between positive and negative reinforcement was in the same direction for both boys and girls, it was relatively greater for boys.

\section{CONCLUSION}

It seems apparent that negative social reinforcement changed the verbal behavior of the $S s$ in the present experiment. In a situation analagous to taking a standardized projective test, Ss showed a relatively greater number of themes following negative reinforcement, indicating that negative reinforcement was associated with a change in response. Since the Positive- and No-Reinforcement conditions did not differ from each other, it is not possible to conclude that positive reinforcement increases the duration of a particular response in such a situation. Such an inference awaits the inclusion of measures such as quantity of verbal material and, perhaps, nonverbal behavior during the session. The interaction between sex and reinforcement had relatively more effect on boys than on girls. This is consistent with an interpretation that boys are more sensitive to the approval of adult males than are girls.

Studies cited above have found positive social reinforcement associated with increases in the responses reinforced, and its removal associated with decrease of such responses. The present study supports only the idea that negative reinforcement reduces the probability of continuing the ongoing response. The differences in findings are probably due to the very different nature of the responses involved. The observations made here were not of díscrete response units as were those of the previous studies. They were related to response duration. Further work might be directed towards a direct comparison of response measures.

\section{REFERENCES}

GEWIRTZ, J., \& BAER, D. The effect of brief social deprivation on behaviors for a social reinforcer. Journal of Abnormal \& Social Psychology, 1958, 56, 49-56.

HARRIS, F., WOLF, M., \& BAER, D. Effects of adult social reinforcement on child behavior. Young Children, 1964, 20, 8-17.

HOROWITZ, F. Social reinforcement effects on child behavior. In $W$. Hartup and N. Smothergill (Eds.), The Young Child. Washington, D. C.: National Association for the Education of Young Children, 1967. Pp. 27-41.

OFFENBACH, S., \& MEYER, W. Adult silence as a reinforcer. Journal of Experimental Child Psychology, 1964, 1, 294-300.

STEVENSON, H., \& HILL, K. The effects of social reinforcement and nonreinforcement following success and failure. Journal of Personality, 1965, 33, 418-427.

WINER, B. J. Statistical principles in experimental design. New York: McGraw-Hill, 1962.

\section{NOTE}

1. Now at the University of Washington. The authors wish to thank the staff of the Fresno State College Laboratory School. This study was conducted by the senior author under the direction of the junior author as part of the requirements for an A.B. in Psychology at Fresno State College.

\section{(Continued from page 65)}

essentially no correlation between these reactions and the Ss' judgments of how much they liked or disliked the stimuli. There were relationships between these reactions and how much the Ss reported that they were affected by the music, but positive correlations were limited almost exclusively to extroverted Ss. The relationships between these variables in introverted Ss assumed the form of negative correlations, and seems to imply that introverts may be misinterpreting bodily sensations. While the GSR reactions seem to be markedly influenced by personality styles, breathing reactions to the music were less subject to extrastimulus variables. Indeed, these latter reactions were correlated with the Ss' perceived effectiveness of the stimuli at approximately the same magnitude as the GSR but were not subject to the influences of extroversion-introversion tendencies. The relationship between the modal breathing amplitude and the Ss' affective responses were highly correlated and indicates that the more a $S$ reports liking a selection, the deeper his breathing becomes. This supports earlier studies (Plutchic, 1959; and Poole et al, 1966) indicating that a strong relationship exists between respiration reactions and emotional responses to auditory stimuli.

\section{REFERENCES}

EYSENCK, H. J. The Maudsley Personality Inventory. San Diego: Educational and Industrial Testing Service, 1962.

HENKIN, R. 1. The prediction of behavior response patterns to music. Journal of Psychology, 1957, 44, 111-127.

PHARES, M. L. Analysis of musical appreciation by means of psychogalvanic technique. Journal of Experimental Psychology, 1934, 17, 119-140.

PLUTCHIC, R. The effects of high intensity intermittent sound on performance, feeling, and physiology. Psychological Bulletin, 1959, $56,113-151$.

POOLE, R., GOETZINGER, C. P., \& ROUSEY, C. L. A study of the effects of auditory stimulation on respiration. Acta-Otolaryngologica, $1966,61,143-152$.

TRAXEL, W., \& WRIDE, G. Changes in GSR while listening to music. Zeitschrift für experimentelle und angewandte Psychologie, 1959,6, 293-309. 